\title{
The interface between primary health care and population health: challenges and opportunities for prevention
}

\author{
Mark Harris $s^{a, b, c}$ \\ a Centre for Primary Health Care and Equity, University of New South Wales, Sydney, Australia \\ b Guest Editor, Vol 26, Issue 1 \\ cCorresponding author: m.f.harris@unsw.edu.au
}

\section{Article history}

Publication date: January 2016

Citation: Harris M. The interface between primary health care and population health: challenges and opportunities for prevention. Public Health Res Pract. 2016;26(1):e2611601. doi: http://dx.doi. org/10.17061/phrp2611601

\section{Key points}

- Primary health care has the potential to improve the population risk of chronic disease by interventions across the '5As' framework

- Barriers at the practice, local health service and system levels prevent this potential from being realised

- Better links and communication need to be established between primary health care and community services and programs to create a more navigable pathway for prevention

- These links need support from primary health care organisations and systems of funding that reward a more integrated approach

\section{Abstract}

Primary health care has the potential to contribute to population health at the individual and population levels. The '5As' (ask, assess, advise/agree, assist and arrange) provide a framework to realise this potential, especially for disadvantaged and vulnerable populations, not only by better organising multidisciplinary preventive interventions within primary health care, but also by linking these interventions with more intensive community and population programs and services, especially for patients with low health literacy.

This requires changes to information systems to prompt and record preventive care, work with practices to engage a range of disciplines, including practice nurses, and development of effective linkages with other services in the local community. This has important implications for the newly established Primary Health Networks in supporting improvement within primary care, and creating linkages and partnerships with a range of organisations involved in delivering preventive interventions in the community. However, prevention in primary health care needs to be underpinned by funding systems that support multidisciplinary and preventive care for a population, rather than simply reactive, episode-based care.

\section{Background}

The prevalence of long-term conditions in Australia places an increasing demand on health services, as well as a burden on individuals and society. These conditions share a number of modifiable behavioural and physiological risk factors - more than $90 \%$ of Australian adults have at least one risk factor, and $64 \%$ have three or more risk factors. ${ }^{1}$ They are amenable to intervention at both the population level and the individual level. Although populations are a key focus of public health and primary health care, services are focused on individuals, but they both have the potential to contribute to improved population health and wellbeing.

The key role of primary health care is related to its population reach - the opportunities for prevention and early intervention that arise in interactions with patients, and the acceptance of this role by the community. More than 
$80 \%$ of the population visit a general practitioner (GP) at least once a year, and GPs have connections (both locational and cultural) with the communities they serve. ${ }^{2}$ Patients attending GPs frequently have one or more risk factors for chronic disease. For example, two-thirds of patients presenting in general practice are overweight or obese, $14 \%$ smoke, and one-quarter have at-risk levels of drinking. ${ }^{3}$

\section{The 5As framework}

The '5As' framework provides a way of understanding and organising the delivery of preventive care in primary health care, including the roles of different providers. Each ' $A$ ' - ask, assess, advise/agree, assist and arrange (Figure 1) - signifies an action by primary health care providers to support their patients to reduce risk and improve their health. This has been used in a number of guidelines for primary health care, including the Royal Australian College of General Practitioners' Guidelines for preventive activities in general practice, and the National Health and Medical Research Council's Clinical practice guidelines for the management of overweight and obesity in adults, adolescents and children in Australia. Progression along the 'As' from assessment to arranging follow-up increases patient motivation and the likelihood of successful behaviour change. ${ }^{4}$ A number of the former Medicare Locals (now merged into Primary Health Networks) developed programs to facilitate prevention in primary care across the $5 \mathrm{As}$, with referral to telephone lifestyle coaching or group lifestyle management programs.

\section{Barriers to preventive care}

The delivery of effective preventive care in primary health care is challenging. A variety of barriers to implementation exist at the patient, practitioner, service and system levels. ${ }^{5}$ For example, GPs may have insufficient time with each patient to offer planned, effective preventive care. Barriers to referral for additional assistance include availability, appropriateness to the individual and cost to the patient, as well as lack of feedback to the GP. ${ }^{6}$ The fee-for-service payment system is not well geared to encouraging and supporting preventive care, especially when multiple disciplines and providers are required to address problems such as obesity. ${ }^{7}$ This means that implementation of the 5As often falls short of its potential in practice, especially the last three steps (advise/agree, assist, arrange). ${ }^{8}$ A system that provides funding for a "package of care for a patient over a specified period of time" may be better able to address this. ${ }^{9}$

Primary health care also has the potential to address health disparities by providing preventive care for disadvantaged populations that suffer an increased burden of chronic disease and risk factors such as obesity. ${ }^{10}$ These patients are likely to have lower health literacy and therefore less capacity to manage their own risk. Access to primary health care has been shown to improve this capacity and reduce health disparities. ${ }^{11}$ However, prevention takes time - some estimates suggest as much as an extra 7.4 hours per week - to perform optimally. ${ }^{12}$ Although there is evidence for the effectiveness of primary health care interventions, patients usually have multiple risk factors that require attention. ${ }^{13}$ Providers working in disadvantaged communities are more likely to be stretched, with insufficient capacity to spend time dealing with these. ${ }^{14}$

These barriers have led some to despair about primary health care playing a significant role in addressing the challenge of chronic disease prevention. Public health practitioners are understandably eager to see that the very limited resources available for prevention are used most effectively. Primary health care is sometimes seen to be competing with population health strategies for scarce resources, and to be less relevant than population health in addressing the underlying social determinants of chronic disease and risk factors. ${ }^{15}$

\section{A pathway between primary health and population health}

Part of the answer is using the 5As approach to provide a pathway between primary health care and interventions provided at the community or population level. For example, primary care providers can 'assist' patients to link with other providers, programs and services, such as community lifestyle programs. This may, for example, involve referral to telephone or ehealth coaching programs and mobile technology, involving greater opportunities for support and interaction outside of the clinical encounter. This linkage is complex, and there is potential for patients with low health literacy or low e-literacy to be lost in the gap between services. ${ }^{16}$ Practice nurses may have a key role as preventive health navigators, especially for vulnerable patients, by providing detailed information and advice about the various options available, helping patients to make choices and following up their use of programs or services.

Figure 1. The 5As for preventive care in general practice

\begin{tabular}{|c|c|c|c|c|}
\hline Ask & $\begin{array}{c}\text { Assess } \\
\text { Risk } \\
\text { Health literacy } \\
\text { Readiness }\end{array}$ & $\begin{array}{c}\text { Advise and agree } \\
\text { Motivational interviewing } \\
\text { Goal setting }\end{array}$ & $\begin{array}{c}\text { Assist } \\
\text { Individual plan } \\
\text { Referral navigation }\end{array}$ & $\begin{array}{c}\text { Arrange } \\
\text { Follow-up } \\
\text { Maintenance }\end{array}$ \\
\hline
\end{tabular}


This approach needs to be supported by practice systems, including routines and work processes, information systems, and linkages with other services and providers. ${ }^{17}$ Decision support systems providing prompts for preventive care and tools for health risk assessment can improve the frequency and quality of preventive care. ${ }^{18}$ The personally controlled electronic health record, now called 'My Health Record', has the potential to improve patient engagement and communication from referral providers back to general practice (thus facilitating future referral). Fulfilling this potential requires a significant increase in adoption of My Health Record across the health system.

The new Primary Health Networks have an important role, both in working with primary health care practices to improve their systems to support prevention, and in linking practices with local public health programs and services. ${ }^{19}$ They can also commission new preventive programs and services to bridge gaps that are not currently being filled, in partnership with state health, local government, nongovernment and community organisations, and Aboriginal health organisations. Some exploratory programs were developed by Medicare Locals with the former Australian National Preventive Health Agency. ${ }^{20}$ It is hoped that these will continue to develop and be more widely implemented.

\section{Conclusion}

There needs to be change at the system level to allow primary health care to achieve substantial improvements in preventive health. The World Health Organization's model of a 'people-centred' health system depends on provision of better information and education to improve health literacy and engagement in decision making at the individual, local and policy levels. ${ }^{21}$ Primary health care is well suited to addressing this at both the individual and community levels. This requires a policy and funding environment that supports improved quality of preventive care, engagement of a range of disciplines, including practice nurses, and integration between providers and services in general practice, private allied health, Aboriginal health and state community services.

\section{Competing interests}

None declared

\section{Author contributions}

$\mathrm{MH}$ is sole author.

\section{References}

1. Australian Institute of Health and Welfare. Risk factors contributing to chronic disease. Canberra: AlHW; 2012 [cited 2015 Nov 5]. Available from: www.aihw.gov.au/ WorkArea/DownloadAsset.aspx?id=10737421546

2. Australian Bureau of Statistics. Australian health survey: health service usage and health related actions, 2011-12. Canberra: ABS; 2013 [cited 2015 Nov 5]. Available from: www.abs.gov.au/ausstats/abs@.nsf/Lookup/4364.0.55.00 2main+features12011-12

3. Britt H, Miller GC, Henderson J, Byaram C, Valenti L, Harrison C, et al. A decade of Australian general practice activity 2004-5 to 2013-14. Sydney: Sydney University Press; 2015 [cited 2015 Nov 5]. Available from: ses.library.usyd.edu.au/ bitstream/2123/11883/4/9781743324240_ONLINE.pdf

4. Jay M, Gillespie C, Schlair S, Sherman S, Kalet A. Physicians' use of the 5As in counseling obese patients: is the quality of counseling associated with patients' motivation and intention to lose weight? BMC Health Serv Res. 2010;10:159.

5. Ampt AJ, Amoroso C, Harris MF, McKenzie SH, Rose VK, Taggart JR. Attitudes, norms and controls influencing lifestyle risk factor management in general practice. BMC Fam Pract. 2009;10:59.

6. Kim KK, Leong LL, Caterson ID, Harris MF. Analysis of influences on general practitioners' referral of obese patients in Australia: a qualitative study. BMC Fam Pract. 2015;16:45.

7. Scott A, Harris MF. Designing payments for GPs to improve the quality of diabetes care. Med J Aust. 2012;196(1):24-6.

8. Harris MF, Islam FM, Jalaludin B, Chen J, Bauman AE, Comino E. Preventive care in general practice among healthy older New South Wales residents. BMC Fam Pract. 2013;14:83.

9. Primary Health Care Advisory Group. Better outcomes for people with chronic and complex health conditions through primary health care. Canberra: Australian Government; 2015 [cited 2015 Nov 5]. Available from: www.health.gov.au/internet/main/publishing.nsf/Cont ent/2D8BCF439DE725CACA257E93001B462A/\$File/ discussion.pdf

10. Australian Institute of Health and Welfare. Australia's health 2014. Canberra: AlHW; 2014 [cited 2015 Nov 5]. Available from: www.aihw.gov.au/WorkArea/ DownloadAsset.aspx?id=60129548150

11. Starfield B, Shi L, Macinko J. Contribution of primary care to health systems and health. Milbank $Q$. 2005;83(3):457-502.

12. Yarnall KSH, Pollak KI, Østbye T, Krause KM, Michener JL. Primary care: is there enough time for prevention? Am J Public Health 2003;93(4):635-41. 
13. Goldstein M, Witlock E, DePue J. Planning Committee of the Addressing Multiple Behavioral Risk Factors in Primary Care Project. Multiple behavioural risk factor interventions in primary care. Summary of research evidence. Am J Prev Med. 2004; 27(2 Suppl):61-79.

14. Norbury M, Mercer SW, Gillies J, Furler J, Watt GC. Time to care: tackling health inequalities through primary care. Fam Pract. 2011;28(1):1-3.

15. Frieden TR. A framework for public health action: the health impact pyramid. Am J Public Health. 2010;100(4):590-5.

16. Taggart J, Williams A, Dennis S, Newall A, Shortus T, Zwar N, et al. A systematic review of interventions in primary care to improve health literacy for chronic disease behavioral risk factors. BMC Fam Pract. 2012;13(1):49.

17. Hung DY, Rundall TG, Tallia AF, Cohen DJ, Halpin HA, Crabtree BF. Rethinking prevention in primary care: applying the chronic care model to address health risk behaviors. Milbank Q. 2007;85(1):69-91.
18. Shih SC, McCullough CM, Wang JJ, Singer J, Parsons AS. Health information systems in small practices: improving the delivery of clinical preventive services. Am J Prev Med. 2011;4(6)1:603-9.

19. Department of Health. Primary health networks: grant program guidelines. Canberra: Australian Government; 2014 [cited 2015 Nov 5]. Available from: www.health.gov. au/internet/main/publishing.nsf/content/phn-guidelines

20. Australian National Preventive Health Agency. Interim national preventive health research strategy 2011-12. Canberra: Australian Government; 2012.

21. World Health Organization Regional Office for Europe. Towards people-centred health systems: an innovative approach for better health outcomes. Copenhagen: World Health Organization/Europe; 2013 [cited 2015 Nov 5]. Available from: www.euro.who.int/_data/ assets/pdf_file/0006/186756/Towards-people-centredhealth-systems-an-innovative-approach-for-better-healthoutcomes.pdf?ua=1

\section{Copyright: (c) (i) (2)}

(c) 2016 Harris. This article is licensed under the Creative Commons Attribution-NonCommercial-ShareAlike 4.0 International Licence, which allows others to redistribute, adapt and share this work non-commercially provided they attribute the work and any adapted version of it is distributed under the same Creative Commons licence terms. See: www.creativecommons.org/licenses/by-nc-sa/4.0/ 